\title{
Postdigital Positionality as a Researcher
}

When I chose to place the concept of positionality next to the word postdigital for the title of this book, I smiled at the possibility that I could simply be creating a form of buzz phrase myself, not unlike those that sit within the McPolicy discourse that I have critiqued over a number of years now. I thought that I will need to be reflexive about that possibility, to explain myself and my reasoning in placing these two words together. Policy aimed at research in $\mathrm{HE}$ is not without its buzz phrases, such as 'world class research', or the huge emphasis placed on 'research excellence' and the elusive, related concept of 'impact'. Both research and teaching policies and practices sit within what has broadly been discussed as a marketisation of $\mathrm{HE}$ or the neoliberal university with features that support 'corporate competitiveness' in the 'global knowledgebased economy' (Slaughter \& Rhoades, 200o). Authors putting forward alternatives to neoliberalism, such as a 'democratic educator' model as opposed to an 'industrial trainer' or 'old humanism' one, tend to focus on what people might do, in terms of reorganisation of values that would further education as an entitlement (Rustin, 2016). Less emphasis has been placed though on how research and scientific progress might contribute to such a restructuring, because many of the popular arguments retain a focus at the level of a critique of neoliberal HE policy. We may soon be entering rather new territory though, as this chapter will discuss.

In The Labour of Words in Higher Education, I examined how particular linguistic patterns could be noticed around certain buzz phrases in HE policy discourse. I undertook a corpus-based Critical Discourse Analysis (CDA) of many strategy texts written about isolated ideas such as 'employability' and 'student engagement' and I explained the research design, methods, terminology, data collected, ethical implications, findings and conclusions drawn from my analysis. These are all recognised stages in any research project that is expected to meet a certain standard of quality and coherence. I also provided a reflexive account of my positionality, which is generally expected of researchers in social scientific, humanities and interdisciplinary research in particular. Positionality is closely related to power and values and to how a researcher might reflexively account for their own personal role and positioning as they conduct a research study. It occurred to me that positionality has a potentially wider role to play 
though, than simply its adoption as a process through which I explain how my values (e.g. as a female of a certain age from a particular background) may have influenced a research study I undertook, or restricted what participants might be prepared to tell me.

This broader vision of positionality is closely related to the notions of both intersectionality and reflexivity and where these concepts may meet in any aspect of our lives in postdigital society. It is intended to contribute to the broad debate on inclusivity and related rational policies in universities, which I argue to be inadequate, due to what these (rather irrationally) exclude. Inclusivity policies in HE generally adopt the rational McPolicy approach where perceived student success might be measured in terms of access, participation and retention and associations between characteristics of students in relation to certain outcomes (Office for Students, 2018, 2019, 2018-2022). An increased focus on equality, diversity and inclusivity in universities has become closely interrelated with the dominant policy discourse of 'the student experience' and 'learner centred' approaches. This has led to universal claims about categories where outcomes might be easily measured, but less attention has been given to more situated, individual accounts of positionality. Furthermore, very little attention has been paid within HE inclusivity policies to the inequities that might be addressed or exacerbated by a broad digitalisation of life and scientific research, including the role of algorithmic activities across opaque, data-driven systems.

As such, I propose that further debate on how we might understand and apply positionality theory in this new postdigital context is now needed. This is firstly, because whatever stance we adopt towards our own research, learning and knowledge, it is now mediated through complex sociotechnical as well as sociocultural interactions. This makes problematising positionality more challenging and this needs to be stated explicitly by those undertaking research. As Cousin has observed, a form of 'positional piety' can sometimes be adopted by researchers who claim moral authority through their affinity with what is being researched (Cousin, 2010: 9). However, there are now new digital filters of many kinds through which what, or whom, we are researching is now mediated. Just as new understandings have emerged about language as 'value laden' (Cousin, 2010: 9), the postdigital context surrounding researchers and those who are being researched cannot be ignored.

Positionality, along with reflexivity became part of methodological conversations in research because these concepts and practices bring insights to situated knowledges. Situating personal experiences within the perspectives of those that they concern, stems from feminist theory (Harding, 1993). Situated knowledges 'disrupt the authority of research and any claims of 
universal knowledge' helping to legitimate the perspectives of diverse individuals (Ulmer, 2017). Such accounts provide powerful alternatives to universal rhetoric like 'the student experience' or 'the international student' because the rich narratives of individuals attest to a fluidity of identity and personal experiences 'among very different and power-differentiated communities' (Haraway, 1988: 580 ). There is though, something of a dilemma in following through my argument, that if positionality is to help inform inclusivity policy it needs to take into account the activities of non-human as well as human beings. Taking such a 'posthuman' approach towards positionality 'decentres' the role of humans, when the situated knowledges argument stemming from feminist theory was intended to 'centre' those whose perspectives risked being marginalised (Ulmer, 2017: 836). Yet in our postdigital society, we cannot be inclusive in inclusivity policy, unless we ensure that all material activities of human and nonhuman bodies are retained in any frameworks that we generate.

Ulmer (2017: 832) argues that 'the posthuman turn has radically shifted what is possible in research methodology' via a 'renewed attention to materiality, vitalism, ecologies, flora, fauna, climate, elements, things, and interconnections'. This has implications across all current and newly emerging academic fields in relation to 'who and what has the capacity to know' and it alters perspectives on what positionality includes:

If humans are not the only possible subjects or objects of study in research, then a wealth of different possibilities emerge. This is why fields such as education, cultural geography, ecofeminism, and philosophy are contending with what it means to do research in an epoch in which humans are a geological force with planetary impact. Critical approaches to inquiry are no exception. (Ulmer, 2017: 832)

My reasoning in writing a book entitled postdigital positionality was not only to capture this wider context of research, but also to demonstrate why positionality has relevance in all of our lives in postdigital society. I could have discussed 'posthuman positionality' alone, but it is the broader postdigital and messy nature of everyone's lives that I have sought to apply positionality to, as it provides a wider overview through which to invite all into this debate.

In this chapter I will firstly, examine some background to how the McPolicy discourse has contributed to bringing about a strong divide between different (but connected) academic activities conducted in universities. A neoliberal form of discourse, as opposed to a classical liberal discourse has altered the positionality of academics as a new liberalism based on the logic and rules of market competition has been applied to the public sector. This has led to 
a 'displacement of public good models of governance, and their replacement with individualised incentives and performance targets, heralding new and more stringent conceptions of accountability and monitoring across the higher education sector' (Olssen, 2016: 129). Olssen argues that 'impact assessment' in particular, 'represents a new, more sinister phase of neoliberal control'. This is a model of accountability that sits at odds with the 'idea of the public good' and also with new cutting-edge scientific research in support of sustainable futures (Peters, Jandrić \& Hayes, 2021a, 2021b, 2021c). Therefore I raise a question that is central to the focus of this book: if we are intent on working towards a set of established inclusive practices in universities, where inequities are addressed, why is it that our HE policies seem intent on excluding so many important aspects of society that now impact on inclusivity for individuals?

In the second half of the chapter, the 'industrialised' nature of science and a global division of labour with its accompanying inequalities (Jandrić \& Hayes, 2019 ) is initially considered. There is the problem of just what vast quantities of scientific data and writing have been now been generated at speed with implications for quality, that have emerged as a by product from the intense focus on impact. There has also been a blurring of lines across what might be thought of as information or knowledge. This has been particularly apparent between politics, journalism and science during the Covid-19 crisis (Rose, 2020). The intense pressure to draw on results from science (which take time to generate in terms of reliability) for policymaking has contributed too. A convergence of relationships across scientific disciplines arise now from mutual interactions between information, biology, politics and the economy. These changes are unfolding before the eyes of a global audience in the virtual airing cupboard and could be profoundly disruptive to who we actually are as humans. Inviting in non-humans as participants is no longer an option, they are a constitutive part of what will become of us.

It is therefore necessary to debate how such scientific convergence might now be reflected in more holistic and organic approaches to critical inquiry and HE policy. In a postdigital society all manner of reconfigurations between technologies and humans are imaginable and indeed probable. In this broad postdigital world view, new possibilities from digitalisation, bioinformation and biodigitalism go way beyond the 'means-end' McPolicy discourse that has developed over decades (Peters, Jandrić \& Hayes, 2021c). Sustainability has taken centre stage supported by cutting edge research, leaving the university with a new, broad educational purpose to step up to. HE now needs new merged and inclusive policies that reflect the postdigital positionality of the university itself, which is the focus of Chapter 6 . 


\subsection{Positionality as Neoliberal or Classical Liberal Discourse}

Neoliberalism has been discussed by Olssen (2016) as 'an application of the logic and rules of market competition to the public sector'. It is helpful though to consider the differences between neoliberal and classical liberal discourse, because it provides broader insight into the structuring of $\mathrm{HE}$ policy during the last three decades:

Classical liberalism represents a negative conception of state power in that the individual was taken as an object to be freed from the interventions of the state, neoliberalism has come to represent a positive conception of the state's role in creating the appropriate market by providing the conditions, laws and institutions necessary for its operation. Whereas in classical liberalism the individual is characterised as having an autonomous human nature and can practice freedom, in neoliberalism the state seeks to create an individual that is an enterprising and competitive entrepreneur. (Olssen, 2016: 130)

Therefore, with regard to the positionality of an individual subject, a shift can be noticed where self-reliance and autonomy in classical liberalism are altered in neoliberal forms of welfare. Instead a perception of self-interested individuals who might slack in their duties in some way results in reliance by the state on monitoring, surveillance, performance appraisal and accountability. With regard to accountability, Olssen points out some of the neoliberal strategies that include:

- contracting out services to the private sector

- increasing competition between units within the public sector

- placing all potentially conflicting responsibilities into separate institutions

- separating the commercial and non-commercial functions of the state

- separating advisory, regulatory and delivery functions into different agencies

- introducing an assortment of accountability and monitoring techniques

- strategies to overcome sources of inequity, inefficiency, corruption

- ensuring international competitiveness, efficiency and excellence

On this basis, 'public-sector reforms relating to health, security or education have sought to restructure the basis of accountability through notions tied to individually attached incentives and targets, and through monitoring and assessment through audits' (Olssen, 2016: 133). Soon after the election of the Margaret Thatcher led Conservative government in the UK in 1979, the first 
major external measurement mechanism introduced in universities was to assess accountability in research. Framework

In the UK, the Thatcher years (1979-1990) sought to restore wealth through a conviction that a free enterprise economy is the only secure basis for individual freedom. Of course, the question could be raised once more: individual freedom from exactly whose positionality? Along with many changes in the mode of regulation of public and private sectors there were changes to the structure of policy discourse (Fairclough, 1989: 177, Hayes, 2019a: 66). A shaping of new professional subjectivities led to 'self-appraising individuals' who were urged to continually notice where they might improve their performativity (Ball, 1997: 263). Such ideas were later developed further under Tony Blair, as the New Labour government took up office in the late 199os.

The Research Assessment Exercise (RAE) was first implemented in 1986, but then again in 1989, 1992, 1996, 2001 and 2008. The RAE was intended to 'survey the quantity and scope of research in order to provide data for the distribution of funding through the Funding Councils' (Olssen, 2016: 134). Disciplinary research structured under certain Units of Assessment (UoAs) was peerreviewed by panels comprised of experts from across the disciplinary areas. The RAE has since been replaced with a Research Excellence Framework (REF, 2014, 2021) which is similar, but the change in language to stress 'excellence' has been accompanied by a move beyond demonstrating productivity and quality of research alone. Olssen refers to a 'new concern to assess and authorise the relevance of research being undertaken in terms of the contribution and significance for the wider society' (Olssen, 2016: 137). The set of criteria used by the assessment panels includes the categories of originality, significance and rigour. In later RAEs work was also codified in terms of 'quality', 'excellence', 'international status' and 'robustness' (Olssen, 2016: 134).

However, the pattern set by RAE and REF for certain academics to be 'returnable' based on items of research published over the period preceding each assessment exercise has also led to a divide between and amongst academic roles in universities. RAE and later REF gave rise to criticism given that 'subjectivity can change depending on who is making the judgement' and 'who gets to read the actual individual pieces and make recommendations' can 'heavily influence the outcome' (Finsden, 2008, 65). Over the years, dissatisfaction amongst academics with these research excellence audits has been apparent in the comments on issues like internal departmental politics that favour some paradigms or forms of research over others. There have been protests at the 
narrowly defined norms for constructing models of academic research success and the lack of support for more varied research approaches and undertakings. Issues regarding routes for maximising publications citations and metrics, stress, anxiety and emotional costs have also been well documented, along with concerns about the competitive nature and complexity in this form of compliance (Olssen, 2016: 135, Barnett, 2000).

\subsection{Separation and Distortion If Positionality Is Not Reflected in Research}

It could be argued too that these frameworks for the measuring of either research or teaching excellence not only separate and segregate university staff from each other, they can also have distorting effects on what is 'reported'. In the case of REF, Olssen (2016:137) discusses 'deep structural fissures at the core of the impact system - concerning what is impact, as well as how to assess it'. Each item of research has its own positionality and context as well as the positionality of the researchers and participants, but an 'epistemic difficulty' arises in assessing impact (Collini, 2009). Collini provides examples concerning the work of historians and how long term the effects might be in terms of any longterm changes in social practices. Olssen adds to this the concerns that:

The assessments of impact are, we could say, inextricably 'entangled' with the privileged positions of the REF panel who establish them. (Olssen, 2016: 138)

Olssen argues further that the impact agenda constitutes a new 'structural selectivity', or 'lever', contributing to the major transformation of academia, extending the neoliberal project from accountability for how academics have met their responsibilities to control over the content of research itself (Olssen, 2016: 139). It is the basis on which research impact is considered in terms of 'uptake' by external parties in industry or policy that Olssen suggests

Constitutes a new definition of research and of what is allowed, and perhaps more importantly not allowed, which is dangerously open to interpretation by the hegemony of dominant and powerful groups. (Olssen, 2016: 139)

These arguments need to be connected with others where an erosion of individual autonomy is taking place across many areas of the university and is as a result altering the positionality of universities themselves as independent agencies within wider political economy. 


\subsection{The Challenges That Have Arisen Surrounding Education Research}

Hammersley (2002) has addressed some of the complexities that have also arisen in relation to the measurement, and practical application of, educational research. In a neoliberal model of monitoring, surveillance, appraisal and accountability, there are conflicting expectations where research into education is concerned. Arguments that education research has failed to properly serve policymaking and practice, tend to lay blame at the door of either researchers themselves, or with policymakers and practitioners (Hammersley, 2002: 59). It is important to look also though, at expectations that have arisen for educational research to serve a form of managerialism, rather than to be channelled into the development of teaching. As such there has been an expectancy that education research will support the project of transforming the education system into a more 'transparent' public management organisation.

The discourse that arises in policy from a conceptualising of a direct relationship between education research and an application to practice resembles an 'engineering model and the metaphors of application, implementation, and dissemination associated with it' (Hammersley, 2002: 77). Such structures can be noticed in McPolicy, particularly in relation to the assumption that educational technology research will feed directly into an enhancement of learning (Hayes, 2019a) but then:

Any failure in this respect is taken to indicate a defect in the way in which one or other activity is being performed. (Hammersley, 2002: 77)

This is a very different model from the role that education research might potentially play if placed at the centre of global plans for sustainable development, as put forward in Education for Sustainable Development: a roadmap (UNESCO, 2O2O). A new interdisciplinary and integrative science that is able to address sustainability though needs a more flexible dialogue between research, education and society 'within the concept of the emerging global digital university ecosystem' (Peters, 2012).

Scientific progress has presented us with new opportunities and challenges in the digitalisation of biology and the biologisation of digital processes, reflecting the need for a different kind of political economy. The emphasis on production that has dominated the industrial age has seen capitalism 'surpass both its material boundaries and the need for concrete people' (De Vos, 2020). In The digitalisation of (inter) subjectivity: a psy-critique of the digital death drive, De Vos suggests that when faced with events that have potential to change both the world and ourselves, we are forced to pose the what will become of us? question. Pointing out that humans always have the capacity to imagine themselves 
as something different, De Vos asks: 'does this not signal that one never simply coincides with oneself, that one is always already other to oneself? (De Vos, 2020). Such then is our potentially reflexive postdigital positionality as we begin to explore the post-industrial green or sustainable economy (Peters, 2012) through bioeconomy. It is now necessary to imagine more empowering and inclusive routes than measuring excellence for research and education policy. Reflexive questions need to be raised too about the nature of reality and who we believe we are as humans. This dialogue needs to 'engage explicitly with values in our decisions about the direction of education' (Biesta, 2009), but also to address some of the recent crises that have befallen research itself in the old industrial model.

\section{Scientific Research, Crises and Convergences}

Ravetz (2016) has raised ongoing concern that despite all of our research measurement and evaluation processes, 'quality control has failed to keep pace with the growth of science' (Ravetz, 2016). Amid the new the biodigital convergence (Policy Horizons Canada, 2020) and resulting reconfigurations to traditional scientific disciplines, there are existing issues of scientific credibility that are now 'older than most junior faculty members' (Bishop, 2019: 435). From concerns over reproducibility (Open Science Collaboration, 2015), abuse of metrics (Wilsdon, 2016), problems of peer review in publishing (Jandrić, 2020) and other areas of integrity, there is a crisis that has effects on what we believe we can actually 'know'. This situation has become more complex as humans have ceased to be able to process big data and algorithms now have considerable agency in all stages of research. This means that questions of reproducibility need to be levelled at both human and non-human researchers together, given their close collaboration, with related challenges for ethics and inclusivity.

In our recent article "Biodigital Philosophy, Technological Convergence, and New Knowledge Ecologies" (Peters, Jandrić \& Hayes, 2021a) we reflected that this crisis in integrity in science has spanned both predigital and postdigital times. Biodigital convergence needs to be explored across all of the emerging ecologies of knowledge with questions and implications of scientific credibility considered alongside other characteristics of biodigital systems, such as: democratisation, decentralisation, geographic diffusion, scalability, customisation and reliance on data (Policy Horizons Canada, 2020). There are other combined factors to discuss too, such as how our political economy has put in place systems of control and rewards that have produced positivist incentives for researchers (Jandrić, 2020b). This has mixed with the 'industrialised' nature 
of science and the global division of labour with its accompanying inequalities (Jandrić \& Hayes, 2019). Short-term contracts afforded to researchers and teachers, where renewal rests in the hands of individuals or lead investigators, has meant that maintaining ideals of independence and integrity becomes increasingly difficult' (Ravetz, 2016). We are faced too with an enormous proliferation of scientific writing which remains unread in its original form (Jandrić \& Hayes, 2019).

\subsection{The Pace and Utility of Scientific Research}

Among other factors that can alter credibility, Sutton (2020) argues that, as we have seen during the pandemic, a 'frantic pace of the 24-hour news cycle and competition from social media mean the bandwidth through which complex ideas must be relayed to the public is very narrow'. Added to this are incentives for broadcasters to gain 'a catastrophising 10-second soundbite' rather than 'a levelheaded exposition' concerning the 'challenges of various competing strategies' (Sutton, 2020). Then there are government scientific advisers who when 'funded by the public purse and bearing considerable social responsibility' should not be excused 'from providing cynical interpretations of data, of questionable validity, and drawn from a weak evidence base, all in order to justify further restrictions' (Sutton, 2020). Given the speed at which innovative ideas quickly become old news, a prioritisation of novelty over replication has developed.

There is a problem that, as research excellence frameworks demonstrate, quality becomes instrumentalised because impact is the name of the game. Even more concerning is the issue that perhaps those who engage in 'shoddy' or 'sleazy' science don't know what is in fact, sub-standard (Ravetz, 2016). Whilst sociological critics have attacked the epistemological foundations of science, less attention has been given to imperfections in its practice (Ravetz, 2016). Picking up on these issues, Bishop (2019: 435) reflects that over the last four decades threats to reproducibility have been recognised but have remained unaddressed. Furthermore, 'many researchers persist in working in a way that is guaranteed not to deliver meaningful results'. Bishop (2019:435) argues though that 'new forces' such as the field of metascience, documentation, and awareness of the issues, may finally help to address irreproducibility, as 'we can no longer dismiss concerns as purely theoretical'. Then there is the fact that 'social media enables criticisms to be raised and explored soon after publication'. In scientific publishing, 'more journals are adopting the registered report format, in which editors evaluate the experimental question and study design before results are collected'. Finally, those who fund research have introduced requirements 'that data and scripts be made open and methods be described fully' (Bishop, 2019: 435). Given that biodigital convergence is surfacing new 
knowledge ecologies, this brings to the forefront questions concerning what our image of science is, or should be, as we face changes that could be profoundly disruptive to our assumptions about society, the economy, and our human bodies (Policy Horizons Canada, 2020, Peters, Jandrić \& Hayes, 2021a). In terms of inclusivity, we might ask though, who in fact should we invite along to such a debate?

\subsection{Including All of Our Environmental Research Partners}

James Ball (2020: 219) makes the point that many of the scientists, technologists and entrepreneurs behind the Internet and major systems and scientific advances under discussion, are actually still alive. If they are willing to participate, such pioneers might be invited to join postdigital debates to discuss new knowledge ecologies, biodigital technologies and the role of the new bioeconomy (Peters, Jandrić \& Hayes, 2021a). There are others though, that now need to be included in these debates and when policy is written, or when ethics is discussed. This is because they already act as partners with us in our research, in new and varied ways, regardless of whether or not, they actually have a voice.

Jasmine Ulmer (2016) raises the question, what if critical inquiries encompassed more than humanity? The stance taken in this book is that they do, but with the acknowledgement that such are the implications from biodigital convergence that critical inquiry itself may experience a shift (Peters, Jandrić \& Hayes, 2021a). Ulmer puts forward the case that critical inquiries take a 'morethan-human turn' via posthumanism, which raises issues for research methodology. Furthermore, taking a position as I have in this book, she argues that:

Knowledge frameworks that privilege the human at the expense of the more-than-human could therefore be viewed as incomplete, as well as a potential injustice to non-human entities. (Ulmer, 2016: 834)

Not only do we now need to attend to and include human entanglements with data and digital technologies, there are other material and non-human environmental actors to account for, as well as connections and relationships described already, where the IoT and AIoT welcome objects like my airing cupboard hot water tank to participate.

\subsection{Human-Centred Approaches to Critical Research Inquiries Are Not Enough}

In critical research studies there is an emphasis on inclusion. Qualitative or mixed methods are applied to support inquiry into questions concerning race, ethnicity, gender, sexuality, class, culture, spirituality, ability, language, and other 
aspects of identity and anyone can offer insights based on their own sociocultural experiences. (Ulmer, 2016: 833). There is a wealth of literature that covers matters of inequity or injustice and fields of study such as Critical Race Theory, disability and gender studies have sought to interpret and better understand the experiences of those who may be marginalised in some form. To this background, arguments from posthuman theory suggest that 'given the state of the planet, human-centred approaches to research may not be enough' and justice involves more than what can be found solely within the realm of human relations (Haraway, 1988, Alaimo, 2016, Braidotti, 2019a, 2019b. Justice then is argued to be also:

material ecological, geographical, geological, geopolitical, and geophilosophical. Justice is a more-than-human endeavour. (Ulmer, 2016: 833)

This stance does not involve removing humans from research but deemphasising the focus on them. Humans being treated for Covid-19 may have symptoms and be required to isolate (Figure 42) but they do not sit in isolation from the contact tracing apps, equipment helping them to breathe, or the locations in which different variants of the virus may have taken hold.

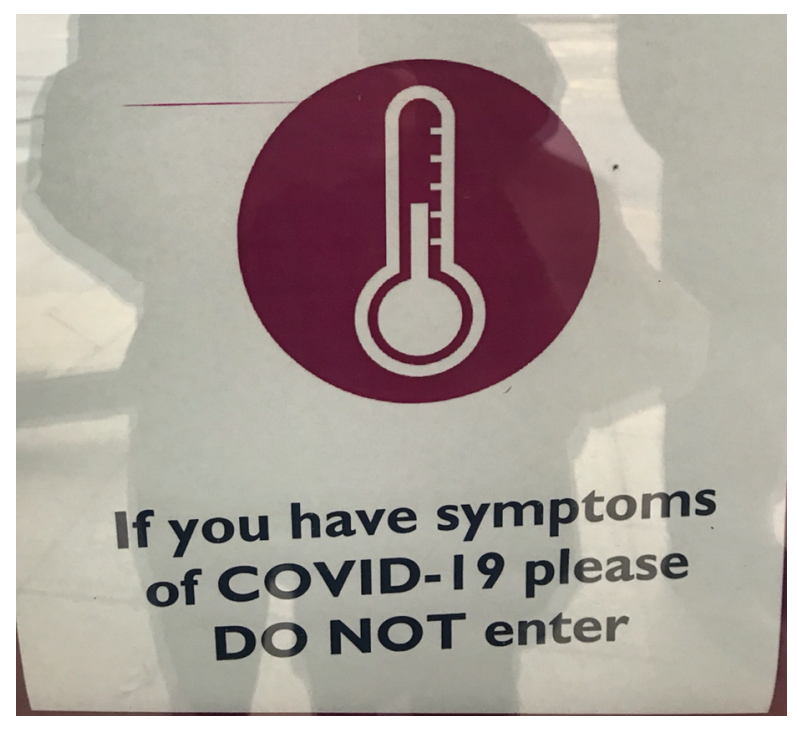

FIGURE 42

A sign asking those with Covid-19 symptoms not to enter a building

This involves recognising that:

non-human elements are always already present. How we live, eat, drink, breathe, commute, hear, see, smell, touch, sense, and experience life are inextricable from our local ecologies. Humans are characters in a cast of many. (Ulmer, 2016: 833) 
Thus, in a posthuman approach any frameworks that privilege the human at the expense of the 'more-than-humans' might be viewed as incomplete which has implications for research methodology and positionality.

\subsection{Implications for Research Methodologies}

Related methodological questions concern who then is producing or contributing to what we understand knowledge to be and from what positionality? Delanty (2011) argues that 'the idea of a critical theory of society' is in itself in 'urgent need of clarification both theoretically and methodologically. At least five major uses of the term can be found within sociological theory Delanty, 2011: 68). There is also a need to interrogate questions that ask how, where, when, with what, and why certain knowledge is being produced (Ulmer, 2016: 834). This raises considerations for researchers in how they locate their own positionality and also render visible other subjective influences within critically reflective frameworks. There are discussions to reflexively include on who or what influenced their research and also how.

Whilst Ulmer is not particularly keen on the term posthuman (rather like postdigtial) she recognises it as useful in the ways that it is invoked by an array of authors whose focus is on matter and the meaning of material things in peoples' lives. She raises the significant point that 'when humans are decentred as the only possible knowers, a wealth of research possibilities emerge' and 'it is no longer enough to produce piecemeal knowledge through interviews, observations, and texts', indeed:

Language - whether it be in the forms of texts, sounds, or images - insufficiently represents the interactions among society, culture, geology, and ecology. (Ulmer, 2016: 834)

By problematising distinctions between and among species and other forms, things, objects or beings the recognition that humans are not the only ones with capacity to 'know' can lead to 'profoundly different ways of thinking about research design' (Ulmer, 2016: 834). There are many different disciplinary traditions (e.g. geology, geography, feminism, cultural studies, science studies, political science, economics, and philosophy, among others) feeding in also to the posthuman debate about how environmental aspects of our existence are to be included.

What can be observed is that during the Covid-19 crisis there are now so many personal narratives attesting to the effects that material elements have in individual lives that such accounts (and their implications for $\mathrm{HE}$ research, teaching and policy) cannot be ignored (Jandrić \& Hayes, 2020a, 2020b, Teräs, Suoranta, Teräs \& Curcher, 2020, Sapon-Shevin, SooHoo, 2020). Humans have 


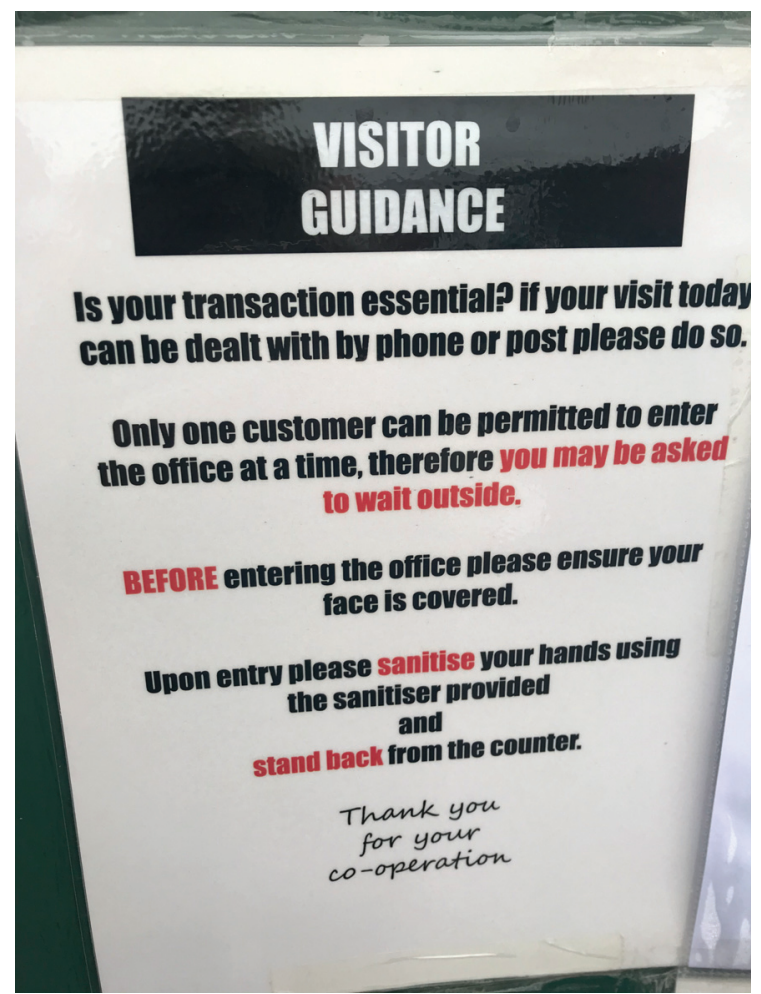

FIGURE 43

A sign listing a set of rules for visitors to an office to observe if their visit is essential

been required to adapt to new sets of rules in language that has separated them from each other, as in Figure 43.

At the same time many of us have spent even more time using devices and material objects to avoid encountering other people, as we follow scientific advice. Therefore, as these human and beyond-human narratives encounter the effects emerging from radical technological changes, there are questions to be raised about scientific research that feed into points concerning $\mathrm{HE}$ policy in Chapter 6.

\subsection{Changing Ecologies of Knowledge about Science, Technology and Policy}

In a paper entitled Changing Ecologies of Knowledge and Action (CEKA), Peter Healey points to the radical changes to the 'familiar landscapes in which science and technology are produced, distributed and used and are accountable to wider society' (Healey, n.d.). In this working paper, Healey raises a set of questions concerning:

1. What kind of science is done? - given accelerating development of new sciences, technologies and fields of radical application, e.g. biosciences; additive manufacturing and advanced IT 
2. How is science done? - given radical improvements in the cost-effectiveness of computing, improved analysis across all fields of science, control of increasingly complex processes in additive manufacturing, increasing reliance on modelling, simulation and 'big data'.

3. Where is science done? - science is increasingly being done beyond the conventional settings of the university and industrial labs e.g. in garage labs, public labs, collaborative facilities of various kinds, some local, some international, sharing opportunities and risks of new technologies, bringing together combinations of industrial, academic and state partners.

4. Who does science? - science is increasingly performed not only by career scientists in university, government and industry labs but also performed directly, or commissioned on behalf of, patient groups, environmental campaigners, entrepreneurs, and hobbyists, with individuals sometimes occupying more than one role in parallel.

5. How is science owned and communicated? - changing approaches to, and uses of, intellectual property regimes and publishing models are developing in the light of open access especially to publicly funded science, and the growth of crowd-funded science.

6. How is science governed, regulated and socially mediated? - despite a growing disconnect between hierarchical institutions and distributed practice, closer inspection reveals a rich variety of linkages, ranging from complete autonomy to full capture by commercial science outlets. Intermediary organisations and networks are playing a developing role in shaping distributed practice through supplying equipment and experimental materials and brokering deals for new scientific outputs or capacities. In macro-issues of governance and regulation many jurisdictions are still evolving (potentially divergent) approaches.

7. What do different sectors of society expect science to do? - states and cities increasingly build political imaginaries around sociotechnical narratives. In parallel to these symbolic uses of science in political attempts to build high-level consensus around broad visions of the future, the pragmatic decisions about particular technologies are often highly contested between different interests and values.

Peter Healey argues that the background to the above developments 'is a set of broader longer term, specific and more immediate changes affecting how science and technology are produced, consumed and perceived (Healey, n.d.: 7).

Such changes have implications for our knowledge of physical and organic things when these are conceived of as code, or as informational building blocks. There are questions concerning manipulation and redesign of life in potentially reductionist ways. In relation to policy benefits, Healey concludes 
that research conducted under CEKA helps with understanding the development of new decentralised and citizen-centred knowledge production across the whole system by which knowledge is produced, validated and utilised. In particular to help us assess:

- whether and in what respects this new production is disruptive, and what new patterns of innovation may be emerging.

- whether and how new modes of doing science affects the balance between the traditional prime governmental target of knowledge in support of economic development, on the one hand, and broad social equity in enjoying the fruits of new knowledge (United Nations, 2012), and democratic accountability/approval for the uses of science, on the other

- policy mechanisms currently being used in the governance and regulation of these new sites and processes for performing science and technology at various scales, with particular attention to issues of safety and quality control

- future science and technology policy pathways, including possible new priorities for the university by which the new knowledge production might be supported and encouraged (Healey, n.d.: 6).

Healey's paper has laid out the broad and dynamic postdigital landscape in which science and technology have converged, with many far-reaching consequences for positionality and university policy that Chapter 6 will now pick up. 